European Association for the Development of Renewable Energies, Environment and Power Quality
International Conference on Renewable Energies and Power Quality (ICREPQ'09)

Valencia (Spain), 15th to 17th April, 2009

\title{
Considerations regarding testing of low voltage equipment endowed with contacts from composite materials type CMC
}

\author{
Dr. Eng. George CURCANU, Eng. Ilie SBORA \\ R\&D National Institute ICMET-Craiova, 144 Calea Bucuresti, 200515 Craiova, Romania \\ phone: +40351 402427; +40351404888; +40351404889 \\ fax: $+40351404890 ;+40251415482$ \\ http://www.icmet.ro, email: LMP@,icmet.ro
}

\begin{abstract}
Within paper there are presented tests performed on low voltage equipment endowed with contacts from composite materials type $\mathrm{CMC}$ and are described the electric circuits for tests at over-load and short-circuit currents according to actual IEC standard 60947 [1]. Also are presented experiments performed on low voltage contactor with CMC type contacts comparatively with those from classical copper-silver contacts.
\end{abstract}

KEYWORDS: low voltage equipment, tests, standards, data acquisition and processing

\section{Introduction}

In the safely and stable operation of low voltage switchgears and controlgears (circuit-breakers, contactors, motor-starters and others) an important role is play by electric contacts due to electrical mechanical stresses during switching operation. That why manufacturers of low voltage electric apparatus search for of new technological solutions regarding the assimilation of new electric contacts realised from microcrystalline materials and composite pseudo-alloys in order to replace classical electric contacts.

Electric contacts realised from composite materials and pseudo-alloys from copper, molybdenum and other metals - codified CMC - were analysed from physical and chemical point of view and also structurally, compared with those realised from copper-silver on more tubes drawn up on samples.

The experiments comparatively performed through electric tests on low voltage contactors have pursued the contacts behaviour at electric wear during switching of short-circuit and overload currents. Electrical tests are performed on electric tests circuits according to the requirements of international standards $[1,2]$.

\section{Requirements of testing standards}

In order to appreciate the withstand ability of low voltage equipment at overload and short-circuit currents passing there are performed type tests according to IEC standards [1,2]. The IEC requirements establish that tests to be performed with five test duties in a certain order and at specified tests parameters (voltages, currents, power factors) $[1,2]$.

Testing standards establish: number of tests to be performed, nominal duty cycles (for switches apparatus), testing circuits, appreciation criteria of test behaviour and apparatus status after test.

As a synthesis of testing standards requirements [1,2] we present below test duties for switching apparatus:

Test sequence 1

(i) Verification of temperature-rise

(ii) Verification of operations and operating limits

(iii) Verification of dielectric properties

Test sequence 2

(i) Verification of rated making and breaking capacities, change-over ability and reversibility, where applicable

(ii) Verification of conventional operational performance

Test sequence 3

- Performance under short-circuit conditions

Test sequence 4 (applicable to contactors only)

- Verification of ability to withstand overload currents

Test sequence 5

(i) Verification of mechanical properties of terminals

(ii) Verification of degrees of protection of enclosed contactors and starters

There should be no failure in any of the tests.

\section{Testing circuit}

Testing circuit for verification of the withstand ability of low voltage equipment at overload and short-circuit currents passing are presented in Figure 1. [3]

The circuit is realised within High Power Laboratory of ICMET Craiova and can be used for testing of all low voltage switchgears: circuit-breakers, contactors, combination circuit-breakers and disconnector, fuses and combinations fuses-disconnectors [3]. 
Circuit I_( $\left(\mathrm{C}_{1}\right)$

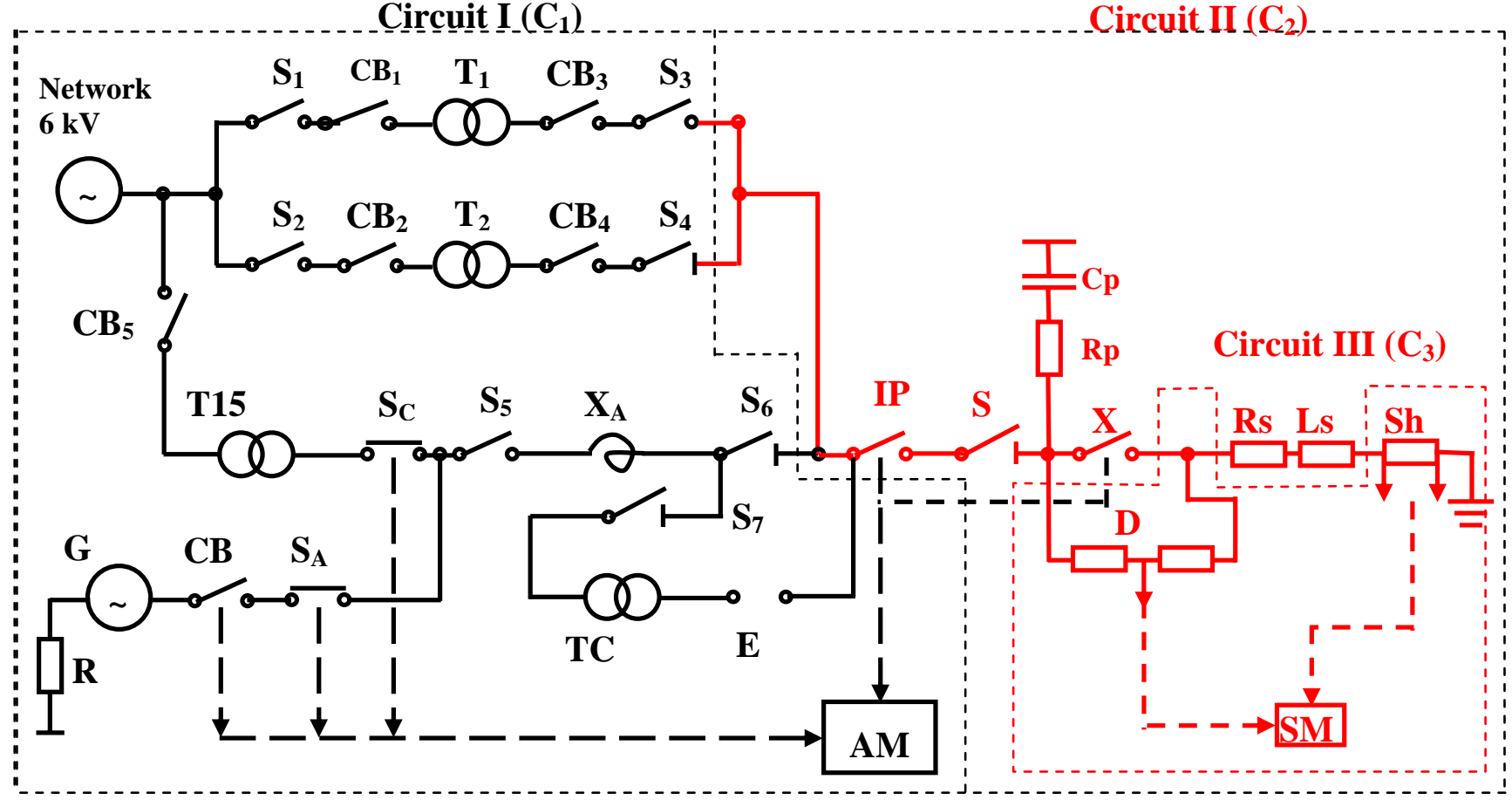

Figure 1 - Testing circuit scheme

$\mathrm{G}$ - short-circuit generator

$\mathrm{S}-$ switches

$\mathrm{CB}$ - circuit-breakers

$\mathrm{T}$ - power transformers

$\mathrm{X}_{\mathrm{A}}$ - reactors for load adjustment
$\mathrm{Rp}, \mathrm{Cp}$ - elements for TRV adjustment

$\mathrm{D}$ - voltage divider

Sh - shunt

AM - automatic programmer

SM - computerised measuring system
E-mobile connection

Rs, Ls - resistors and reactors

$\mathrm{C}_{1}$ - voltage supply circuit

$\mathrm{C}_{2}$ - load adjustment circuit

$\mathrm{C}_{3}$ - measuring circuit

\section{Experiments on low voltage contactors with CMC type contacts}

\section{A. Experiments for choosing the contacts with composite materials type CMC}

In choosing the composite materials for the electric contacts were taken in consideration physical, chemical and structural properties of composite materials and pseudo-alloys, in comparison with classic materials properties.

As prime matter for the new CMC type contacts was used composite microcrystalline material in microstructures having at base copper and molybdenum in larger percent and other materials (yttrium, zirconium etc.) in lower percent. For these materials were drawn up three tubes with three samples: $\mathrm{CMC}_{1}, \mathrm{CMC}_{2}$ and $\mathrm{CMC}_{3}$ for which were performed physical-chemical-structural tests, mechanical-physical tests and electrical tests [4,5].

Physical-chemical-structural tests were performed through chemical analysis, determination of corrosion resistance, metallographic analysis of microstructure and microweldings $[4,5]$.

Physical-mechanical tests were performed by determination of Vikkers hardness, density, mechanical characteristics in longitudinal direction and mechanical resistance in transversal direction [5].

Electric tests were performed by determination of volume electric resistance and of resistance at wear of the contacts within switching processes [6].

\section{B. Electric tests of resistance at wear}

Electric contacts from composite materials type CMC were mounted on a $230 \mathrm{~V} / 400$ A contactor type AC3 for electrical verifications. These contacts should have a mean life duration equal to load operating aptitude of the low voltage apparatus on which there are mounted according to IEC 60947 standards [1,2].

For a correct appreciation of resistance at wear of the new materials type CMC based on pseudo-alloys made from composite materials, comparatively to resistance at wear of the of classical copper-silver materials, there were performed electric tests according to IEC standards $[1,2]$. Tests program was the following [6]:

\section{Test sequence 1:}

Temperature-rise test at rated current $\mathrm{In}=400$ A (with new contacts made from $\mathrm{CuMo}[\mathrm{X} \%]$ at environment temperature $21{ }^{\circ} \mathrm{C}$ ): (Table 1) [6]

Measuring point: contact pastille $\mathrm{CMC}$.

\section{Table 1}

\begin{tabular}{|l|c|c|c|}
\hline No. & {$[\% \mathrm{Mo}]$} & Temperature $\left[{ }^{\circ} \mathrm{C}\right]$ & Temperature-rise $[\mathrm{K}]$ \\
\hline 1 & 4.36 & 75.96 & 54.96 \\
\hline 2 & 3.21 & 75.58 & 54.58 \\
\hline 3 & 7.68 & 77.06 & 56.06 \\
\hline 4 & 11.54 & 78.98 & 57.98 \\
\hline 5 & 8.97 & 77.49 & 56.49 \\
\hline
\end{tabular}

Test sequence 2:

I) verification of making and breaking capability at parameters: $\mathrm{I}=3200 \mathrm{~A}, \mathrm{U}=400 \mathrm{~V}, \cos \varphi=0.35$ in cycles: 50 openings and 50 closings (see Figure 2) [6]. 
II) verification of conventional operation at parameters: $\mathrm{I}=800 \mathrm{~A}, \mathrm{U}=400 \mathrm{~V}, \cos \varphi=0.35$ in cycles: 50 openings (see Figure 3) [6].

Test sequence 3:

Verification of operation in short-circuit conditions at parameters: $\mathrm{I}=18 \mathrm{kA}, \mathrm{t}=1 \mathrm{~s}, \cos \varphi=0.1$ (see Figure 4) [6]

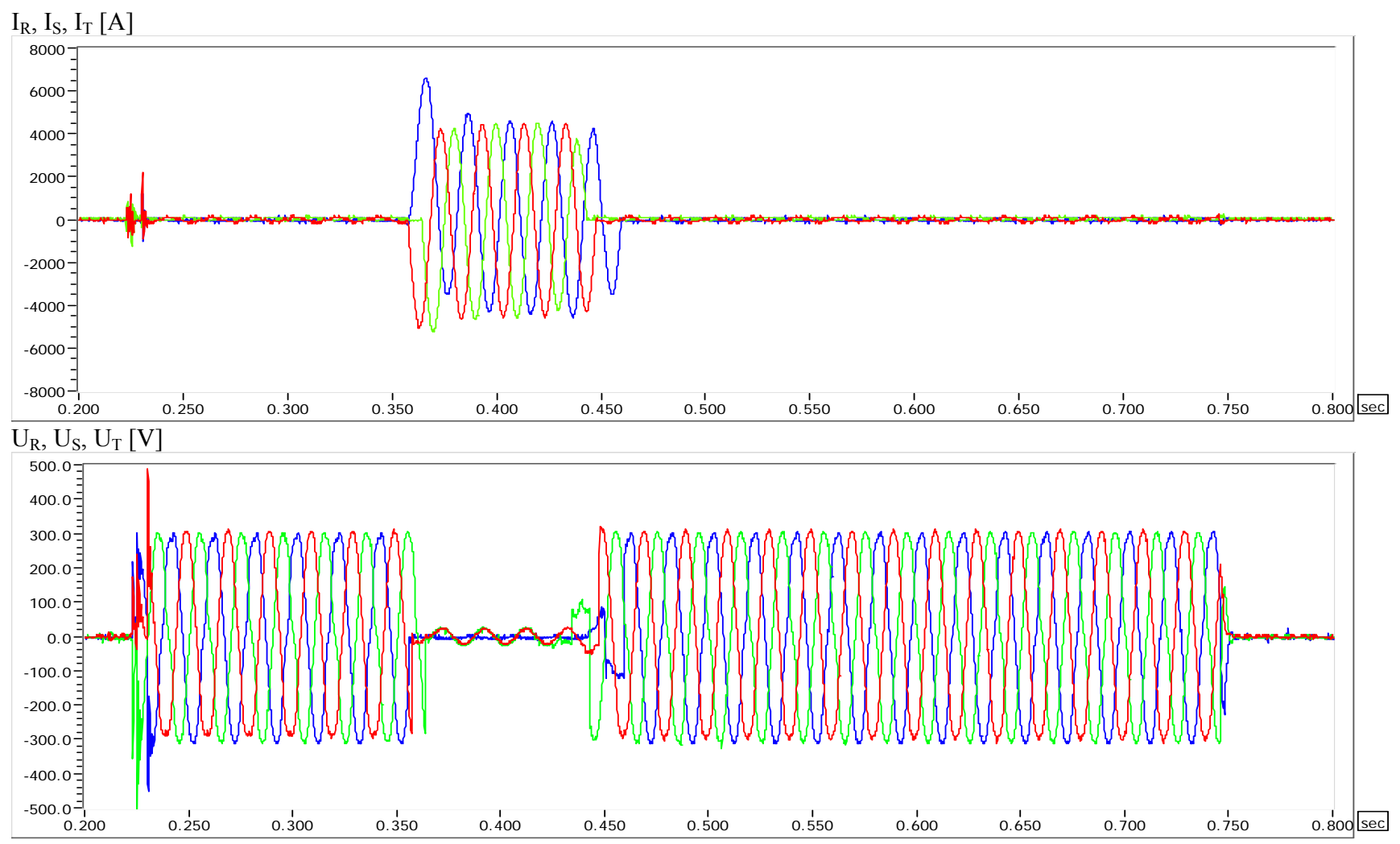

Figure 2 - Oscillogram from test sequence 2-I
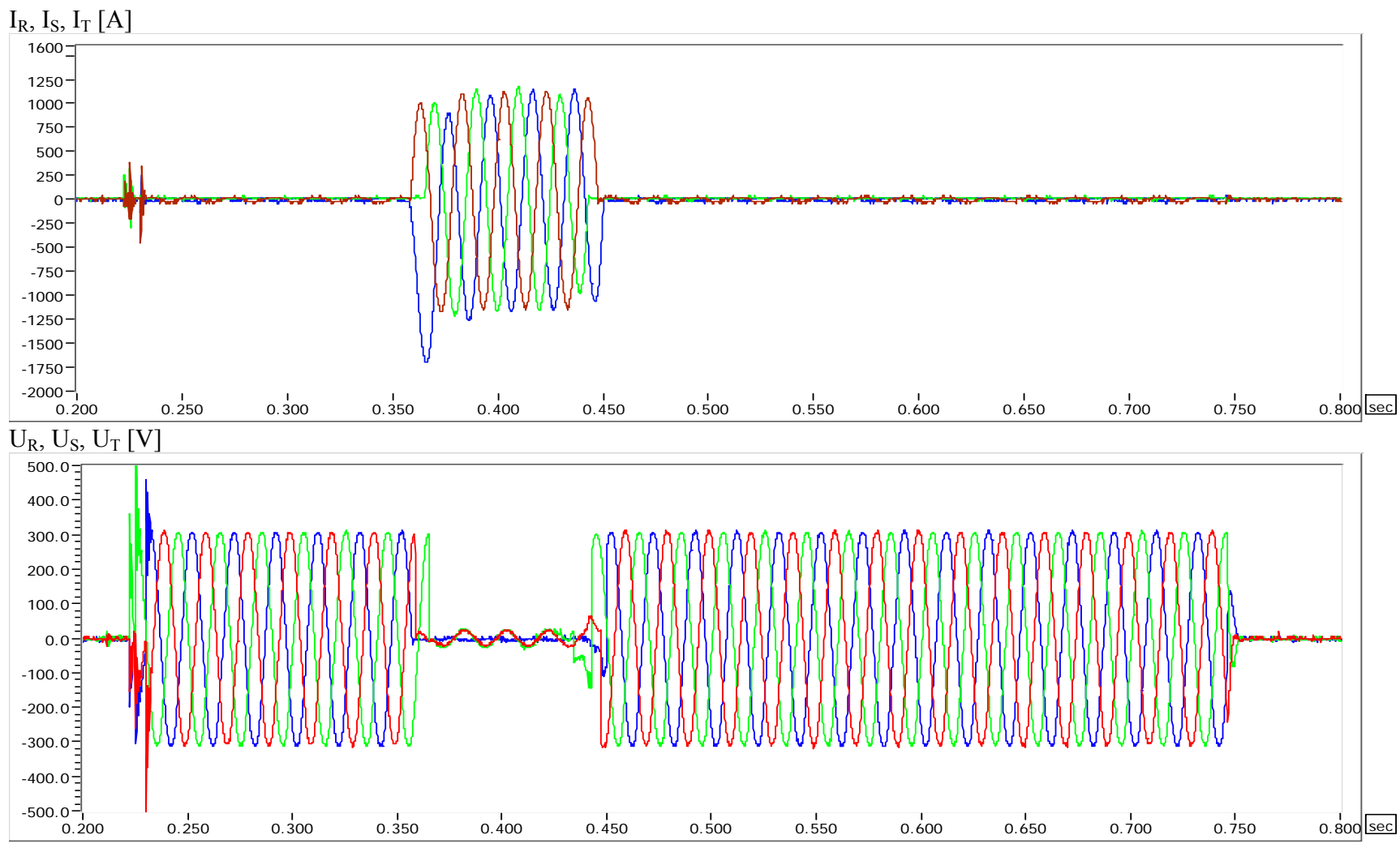

Figure 3 - Oscillogram from test sequence 2-II 


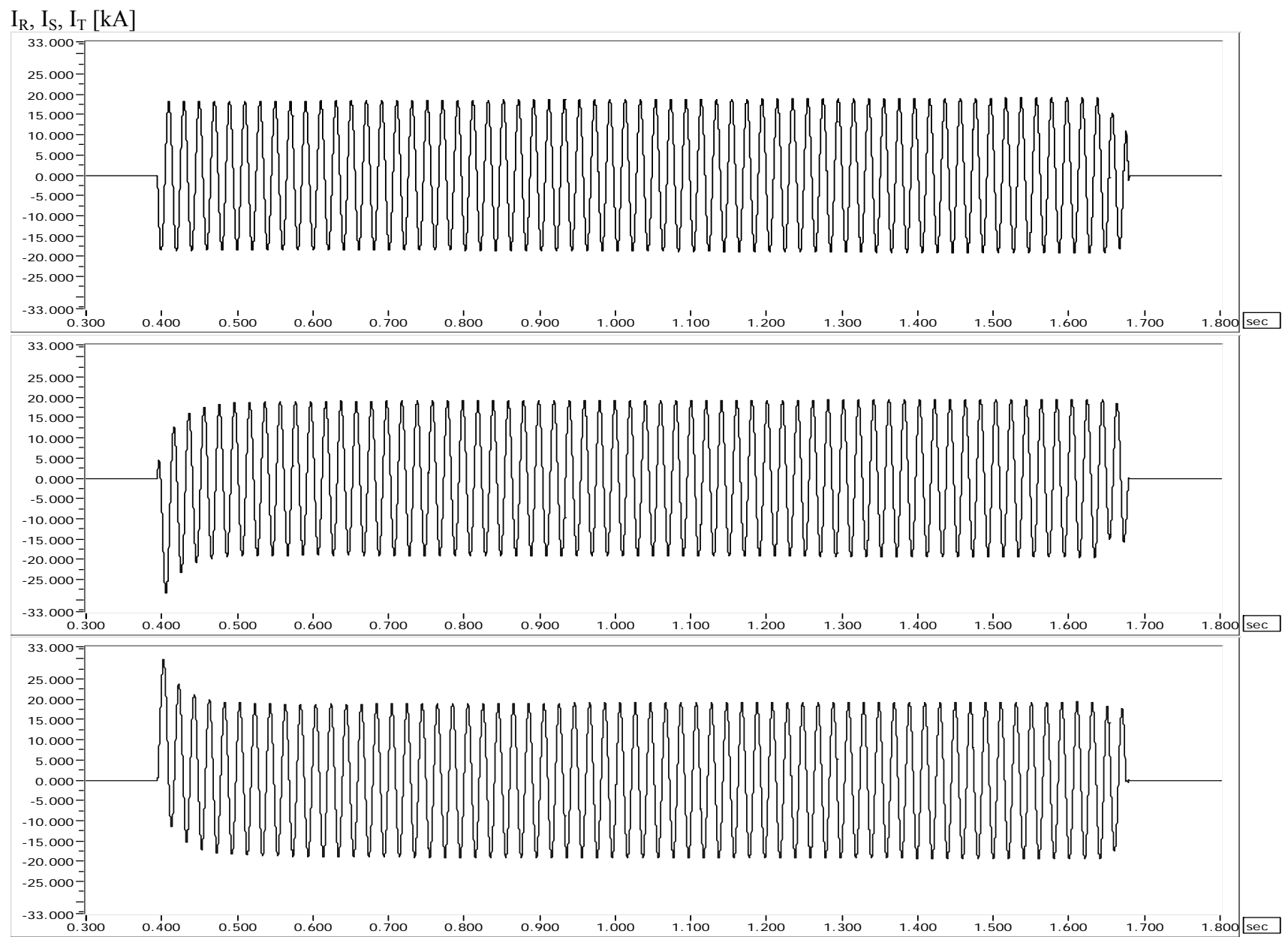

Figure 4 - - Oscillogram from test sequence 3

Notes: Test sequence 5 is not necessary. During all test sequence there was no melting or deformations of contacts peaks but only small pearls. The aspect of fix and mobile contacts after tests are presented in Figure 5.

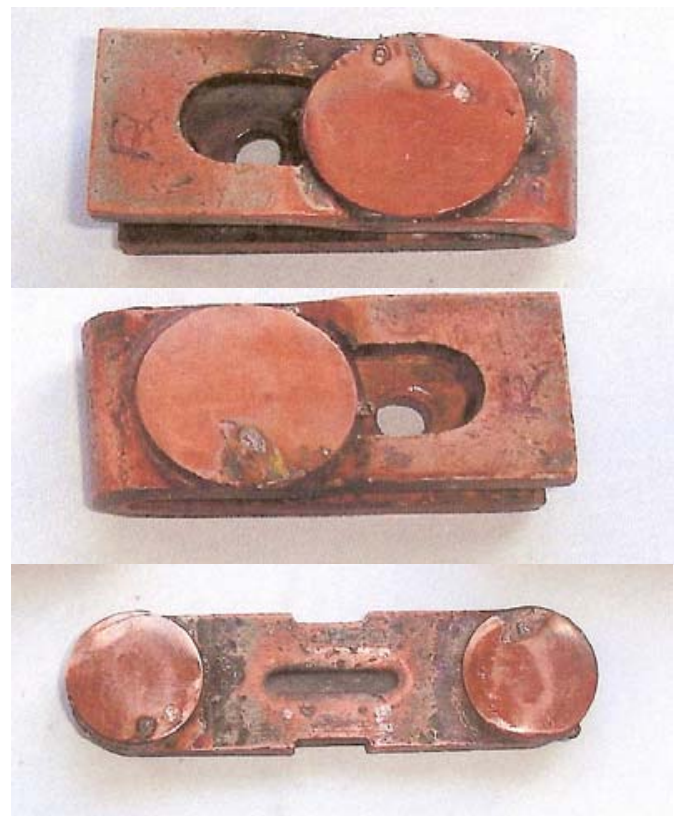

Figure 5 - The aspect of fix and mobile contacts after tests

\section{Conclusions}

- Experiments performed on 400 V/400 A contactor allowed verification of CMC type contacts which had a good behaviour at shortcircuit currents, without melting and no brokens.

\section{REFERENCES:}

[1] *** - IEC 60947-4.1/2002: Contactors and motorstarters.

[2] *** - IEC 60947-1-2-3/2005: Low voltage switchgears and controlgears.

[3] G. Curcanu, C. Inacu, D. Truta - Considerations regqarding testing of low voltage equipment at electrical arc and thermal factor actions ICREPQ'07, Sevilla, Spain.

[4] V.G. Grechanyuk, B.M. Emelianov et. al. Issledovanie korrozionnoi stoikosti tolstah vakuumnah kondensatov $\mathrm{Cu}-\mathrm{Mo}$ v vodnah sredah - in Problema spetalinoi metallurghii, Nauka dumka. 1986.

[5] *** - Specificatia Tehnica Nr. 001/2001 - Materiale pentru contacte electrice tip MDK

[6] *** - Test Report 10371/2005 for 380 V/500 A contactor 